\title{
LETTER
}

\section{Microsphere contrast echocardiography in the critical care complex}

\author{
David G Platts*1 and John F Fraser ${ }^{2,3}$ \\ See related research by Saranteas et al., http://ccforum.com/content/15/1/R54
}

The paper by Saranteas and colleagues [1] in the previous issue of Critical Care describes the use of transthoracic echocardiography (TTE) for detection of ventricular thrombus in postoperative patients in the critical care unit. While we agree that TTE is a fundamental diagnostic imaging tool that enhances detection of anatomic and physiologic abnormalities within the critical care complex, we would like to make several comments regarding its utility in this clinical setting. In up to $25 \%$ of TTE scans performed in the critical care complex, the images are nondiagnostic despite operator excellence, and this fact can have a significant impact on patient diagnosis and management [2]. We agree with the authors that, owing to the suboptimal spatial orientation of the transducer in relation to the left ventricular apex, transoesophageal echocardiography may not help in these cases.

However, we would like to propose that the use of contrast echocardiography be expanded in the critical care setting in order to clarify those 'vague results' rather than have those same suboptimal, nondiagnostic images reinterpreted by another reader. Even experienced readers of TTE cannot make an accurate interpretation of 'vague' or suboptimal TTE images. In these cases, it is clearly recommended that contrast echocardiography be performed to improve diagnostic clarity [3].

Contrast echocardiography, using contrast microspheres coupled with contrast-specific ultrasound imaging modalities, overcomes many of the limitations that cause suboptimal echocardiograms in the critical care environment [4]. Contrast echocardiographic imaging has been assessed in the critical care setting and has been shown to be safe, feasible, and accurate $[2,5]$. The recent contrast guidelines of the American Society of Echocardiography state that 'the availability of contrast

*Correspondence: david_platts@health.qld.gov.au

'Department of Echocardiography, The Prince Charles Hospital, Rode Road, Chermside, Brisbane, QLD 4032, Australia imaging in the [intensive care unit] enhances overall efficiency, diagnostic accuracy, and cost-effective patient management and has no incremental risk for death compared with non-contrast echocardiography' [3]. For patients who are in the critical care setting and who have nondiagnostic TTE results, a contrast-enhanced TTE should now be at the forefront of a diagnostic algorithm.

\section{Abbreviation}

TTE, transthoracic echocardiography.

\section{Competing interests}

The authors declare that they have no competing interests.

\section{Author details}

'Department of Echocardiography, The Prince Charles Hospital, Rode Road, Chermside, Brisbane, QLD 4032, Australia. ${ }^{2}$ Critical Care Unit, The Prince Charles Hospital, Rode Road, Chermside, Brisbane, QLD 4032, Australia. ${ }^{3}$ Critical Care and Anaesthesia, School of Medicine, University of Queensland, Georges Street, Brisbane, QLD 4072, Australia.

Published: 6 April 2011

\section{References}

1. Saranteas T, Alevizou A, Tzoufi M, Panou F, Kostopanagiotou G: Transthoracic echocardiography for the diagnosis of left ventricular thrombosis in the postoperative care unit. Crit Care 2011, 15:R54.

2. Reilly JP, Tunick PA, Timmermans RJ, Stein B, Rosenzweig BP, Kronzon I: Contrast echocardiography clarifies uninterpretable wall motion in intensive care unit patients. J Am Coll Cardiol 2000, 35:485-490

3. Mulvagh SL, Rakowski H, Vannan MA, Abdelmoneim SS, Becher H, Bierig SM, Burns PN, Castello R, Coon PD, Hagen ME, Jollis JG, Kimball TR, Kitzman DW, Kronzon I, Labovitz AJ, Lang RM, Mathew J, Moir WS, Nagueh SF, Pearlman AS, Perez JE, Porter TR, Rosenbloom J, Strachan GM, Thanigaraj S, Wei K, Woo A, Yu EH, Zoghbi WA; American Society of Echocardiography: American Society of Echocardiography Consensus Statement on the Clinical Applications of Ultrasonic Contrast Agents in Echocardiography. J Am Soc Echocardiogr 2008, 21:1179-1201.

4. Platts D, Fraser JF: Contrast echocardiography in critical care: echoes of the future? A review of the role of microsphere contrast echocardiography. Crit Care Resusc 2011, 13:44-55

5. Costa JM, Tsutsui JM, Nozawa E, Morhy SS, Andrade JL, Ramires JF, Mathias W Jr.: Contrast echocardiography can save nondiagnostic exams in mechanically ventilated patients. Echocardiography 2005, 22:389-394.

doi:10.1186/cc10122

Cite this article as: Platts DG, Fraser JF: Microsphere contrast echocardiography in the critical care complex. Critical Care 2011, 15:417. 